\title{
Toxin Accumulation in Avena Species after Different Spray Inoculation by Fusarium graminearum and $F$. culmorum
}

\author{
S. ŠLiková*, E. Gregová and M. PASTiRČÁK \\ National Agricultural and Food Centre, Research Institute of Plant Production, \\ Bratislavská cesta 122, 92168 Piešt’any, Slovak Republic
}

(Received 25 September 2018;

Accepted 5 September 2019)

\begin{abstract}
Avena spp. were artificially inoculated with Fusarium culmorum Sacc. (FC) and F. graminearum Schwabe (FG) causing Fusarium head blight (FHB). This disease is often accompanied by the accumulation of Fusarium mycotoxins mainly deoxynivalenol (DON) in grains. The contaminated grains with this mycotoxin are toxic to their consumers. Genotypes Avena spp. with low DON accumulation in grains can be used as genetic resources suitable for the formation of new resistant varieties of oats against FHB caused by fungi FC and FG. The aim was to find out and to compare the potential for mycotoxin accumulation in grains between genotypes of Avena spp. after artificial inoculation panicles by FC and FG using three spray methods and identify genotypes of Avena (A. abyssinica, A. byzantina, A. canariensis, A. fatua, A. ludoviciana, A. nuda, A. sativa, A. sterilis, A. strigosa) with low toxin accumulation in whole grain. The average accumulations of DON in the grains of Avena spp. gradually increased from the spray inoculation $\left(0.68 \mathrm{mg} \cdot \mathrm{kg}^{-1}\right)$, spray + polyethylene (PE) bag cover $24 \mathrm{hrs}\left(2.75 \mathrm{mg} \cdot \mathrm{kg}^{-1}\right)$ and spray $+\mathrm{PE} \mathrm{bag} / 48 \mathrm{hrs} .\left(9.46 \mathrm{mg} \cdot \mathrm{kg}^{-1}\right)$ methods. We found out that after application of each used method, the high DON accumulation in grains was found in A. canariensis, and low DON levels were found in A. byzantine and A. sterilis.
\end{abstract}

Keywords: Avena spp., mycotoxin, Fusarium spp., spray inoculations

\section{Introduction}

The oat grain contains specific substances with a positive effect on human health. It is a rich source of $\beta$-glucan, which is known to be responsible for a LDL-cholesterol reducing effect and thus reduces the risk of cardiovascular disease (CVD) (Othman et al. 2011). In addition, oat kernels contain more than 20 unique polyphenols, avenanthramides, which have been shown to have strong antioxidant activity in vitro and in vivo (Meydani 2009). Moreover, oats are cereals with the highest protein content in grains among routinely consumed cereals including corn and rice (Lásztity 1998) and very favourable lipid profile. Its nutritional profile and other useful characteristics such as stabilisation due to its high water-holding capacity (Welch 1995) making oat flour great and often used component for baby food. For these benefits, oat grains are also often part of breakfast cereals;

\footnotetext{
*Corresponding author; E-mail: svetlana.slikova@nppc.sk
} 
oat bran and flour is added to wheat bread or various bakery products, biscuits, cookies, probiotic drinks, and in certain daily doses may be appropriate in the diet of celiac patients. However, for a safe consumption, grains must be healthy and free of mycotoxins, which are dangerous to human and animal health. These toxins can accumulate at higher or lower level in the grains after Fusarium spp. infestation of the oats depending on many factors. The highest contamination of the grains with mycotoxins occurs after infestation of oat during the anthesis stage through the floret mouth (Tekle et al. 2012). According to the multi-annual surveys on the occurrence of mycotoxins in oat grains grown in various locations in Europe, oats are most frequently contaminated with Fusarium mycotoxins DON, T-2 toxin and HT-2 toxin (Edwards 2017; Fredlund et al. 2013; Hietaniemi et al. 2016; Hofgaard et al. 2016; Nathanail et al. 2015; Schöneberg et al. 2018). Specifically, the mycotoxin DON is produced mainly by F. graminearum $(\mathrm{FG})$ (Gibberella zeae teleomorph) and F. culmorum (FC) and the main producers of HT-2 and T-2 in oats are fungi F. langsethiae (FL) and F. sporotrichioides (Hofgaard et al. 2016; Edwards et al. 2012; Schöneberg et al. 2018). Hofgaard et al. (2016), observed that the prevalence of FG negatively influences the HT-2 + T-2 content whereas FL had not impact on the DON level. Despite the competitive features of the FG, only a slight correlation has been found between HT-2 + T-2 and DON mycotoxins content in oat grains, leading to a conclusion that the HT-2 and T-2 producers (main producer fungi FL) require different environmental conditions than DON producers (main producers FG and FC). Moreover, no association has been found between the amount of FG and FL DNA in contaminated oats (Xu et al. 2014; Hofgaard et al. 2016). In recent years an increased incidence of oat samples with an exceeded limit of DON content has been found in the locations of major European producers of this crop such as Russia (Gavrilova et al. 2016), Norway (Hofgaard et al. 2016) and western Sweden (Fredlund et al. 2013). There has also been observed a change in the prevalence of species causing FHB and species responsible for DON production. The prevalence of FG was also found in grain samples of oats grown in the northern regions of Russia. According to Gavrilova (2016), FG are being adapted in this area, which is related to the change in global warming conditions, which results in the penetration of new pathogens into new areas. The investigation of Fusarium spp. incidence on Norwegian oats samples has shown a shift in the relative spp. prevalence towards more FG, rather than FC, as main producers of DON in oats kernels grown in Norway (Hofgaard et al. 2016). Similar results were obtained by analyses of Swedish oats, when correlation analysis showed significant relation between concentration of DON and FG content $(\mathrm{r}=0.77, \mathrm{P}<0.001)$. Legislative limits for DON in unprocessed oats and oat-based foods have been set by the European Union at 1.750 and $0.750 \mathrm{mg} \cdot \mathrm{kg}^{-1}$, respectively (Commission Regulation 2006). The oats with more DON than allowed legal limit have a negative economic impact on growers and affect both domestic and foreign grain exports as well as the processing industry. From an economic and ecological point of view, it has been shown that the most suitable way to control the prevalence of FHB and mycotoxins is to cultivate plants resistant to pathogens producing mycotoxins. In Norway, significant accomplishments have been achieved by performing multi-annual testing $(9 \mathrm{yr})$ of cultivars and breeding lines of Avena sativa L. to FG with effort to improve FHB resistance in oat 
(Tekle et al. 2018). During extensive screen of the Avena germplasm collection (hulled and hull-less cultivars, landraces and selections lines) for FHB, implemented in Russia, resistant oat genotypes that can be used in the process of generating new varieties of oats (Gagkaeva et al. 2011) have been identified. Bjørnstad et al. (2017), identified oat lines with consistently low DON levels and QTLs for DON after infection of plants by spawn inoculation with FG-infected oat kernels and thus provided genetic tools for breeders. It is well known that even wild relatives of cereal can be a good source of new valuable features including disease resistance. It has been reported that some genotypes of Avena spp. revealed resistance against FC and accumulation of DON in several field tests (Gagkaeva et al. 2017).

The aim of our experiment was to detect and compare DON accumulations in Avena spp. grains after inoculation with artificial infection by FC and FG as the major producers of this mycotoxin following the application of a spray artificial infection with a different initiation of the infection process (1) spray, (2) spray $+\mathrm{PE}$ bag/24 hrs, (3) spray $+\mathrm{PE}$ bag/48 hrs and to find possible sources to improve resistance to DON accumulation for oat breeders.

\section{Materials and Methods}

\section{Plant material}

The examined set for spray inoculation method included $\mathrm{n}=22$ genotypes from 9 Avena spp.: A. strigosa Schreb. $(2 \mathrm{n}=14 ; \mathrm{n}=1) ;$ A canariensis Baum $(2 \mathrm{n}=14 ; \mathrm{n}=1) ;$ A. abyssinica Hochrs.t. $(2 \mathrm{n}=28 ; \mathrm{n}=1) ;$ A. stativa L. $(2 \mathrm{n}=42 ; \mathrm{n}=9) ;$ A. nuda $\mathrm{L} .(2 \mathrm{n}=42$; $\mathrm{n}=6) ;$. fatua L. $(2 \mathrm{n}=42 ; \mathrm{n}=1) ;$ A. sterilis $\mathrm{L} .(2 \mathrm{n}=42 ; \mathrm{n}=1) ;$. ludoviciana Durieu. $(2 \mathrm{n}=42 ; \mathrm{n}=1) ;$. byzantina $\mathrm{K}$. Koch $(2 \mathrm{n}=42 ; \mathrm{n}=1)$. (2) The examined set for spray + $\mathrm{PE}$ bag/24 hrs inoculation method included $\mathrm{n}=15$ genotypes from $\mathrm{z} 9$ Avena spp., with A. stativa L. $(2 \mathrm{n}=42 ; \mathrm{n}=5)$ and $A$. nuda L. $(2 \mathrm{n}=42 ; \mathrm{n}=3)$. (3) The examined set for spray $+\mathrm{PE} \mathrm{bag} / 48 \mathrm{hrs}$ inoculation method included $\mathrm{n}=13$ genotypes from 9 Avena spp.: with $A$. stativa L. $(2 \mathrm{n}=42 ; \mathrm{n}=3)$ and $A$. nuda L. $(2 \mathrm{n}=42 ; \mathrm{n}=3)$.

\section{Inoculum production}

The fungal colonies of FG (strain VURV02MP) and FC (strain VURV03MP) were grown on potato dextrose agar plates (PDA, Difco) or synthetic nutrient agar plates (SNA) (Nirenberg 1976) at $25^{\circ} \mathrm{C}$ for twenty-one days in dark. The isolates were initially obtained from naturally infected wheat spikes collected in different regions of Slovakia and are maintained in the VURV collection (NPPC VURV, Piešt'any, Slovakia). The inoculum was prepared by the surface flooding of agar plates with sterile distilled water from $90 \mathrm{~mm}$ diameter Petri dishes and scraping the sporulated aerial mycelium with a loop. Concentration of inoculum was measured with hemacytometer and adjusted to approximately $5 \times 10^{6}$ propagules per $\mathrm{ml}$. Approximately $1 \mathrm{ml}$ conidial suspension of the inoculum $\left(5 \times 10^{6}\right.$ per $\left.\mathrm{mL}\right)$ was applied to each oat panicle. 
Field experiment - Spraying method (spray) and Spraying method combined with polyethylene bag coverage/24 hrs (spray + PE bag/24 hrs)

In 2014 and 2015 field experiments (experiment with spray method and experiment with spray + PE bag/24 hrs) were established under natural conditions in Piešt'any. The location is $160 \mathrm{~m}$ above sea level in a corn-wheat production region. Weather conditions were in experimental years 2014 (May, Average temperature $=15.03{ }^{\circ} \mathrm{C}$, Rainfall $=81.30 \mathrm{~mm}$; June $18.97{ }^{\circ} \mathrm{C}, 34.90 \mathrm{~mm}$ ) and 2015 (May $14.80{ }^{\circ} \mathrm{C}$, $63.80 \mathrm{~mm}$; June $19.42{ }^{\circ} \mathrm{C}, 16.70$ $\mathrm{mm}$ ) obtained from meteorological weather station that is located near the plot experiments in Research Institute of Plant Production in Piešt'any. There were five rows per plot with $1 \mathrm{~m}$ length and $150 \mathrm{~mm}$ row spacing. Each isolate was used in three replicates. The panicles in one plot were artificially inoculated with the isolate FC or FG (end of May and until mid-June) by methods: (1) spray - panicles were sprayed $3 \times$ after 2 days after inoculation with Fusarium and were not covered with plastic bag, (2) spray + PE bag/24 hrs described by Mesterházy (1978) - panicles were covered with a plastic bag for $24 \mathrm{hrs}$ after inoculation. All bags were then removed after $24 \mathrm{hrs}$. In the mature stage, 50 panicles from each genotype were handpicked and grains were manually separated.

\section{Greenhouse experiment - Spraying method combined with polyethylene bag coverage/48 hrs (spray + PE bag/48 hrs)}

This experiment was carried out according to the modified method described by Mesterházy (1978). In 2016, the greenhouse experiment was established with 30 seeds from each genotype of Avena spp. These seeds were sown in 3 pots per treatment $(5$ seeds in one pot). The panicles of Avena spp. were sprayed with FC or FG inoculum in three replicates and then were covered with plastic bags for $48 \mathrm{hrs}$. In the mature stage, panicles were collected from each Avena spp. and grains were manually separated.

\section{Statistical analysis}

A commercial competitive enzyme-linked immunosorbent assay (ELISA kit) was used to determine the DON concentration in oat samples (Ridascreen Fast DON; RBiopharm, Darmstadt, Germany) with limit of detection $<0.2 \mathrm{mg} \cdot \mathrm{kg}^{-1}\left(\mathrm{mg} \cdot \mathrm{kg}^{-1}\right)$ and limit of quantification $0.2 \mathrm{mg} \cdot \mathrm{kg}^{-1}\left(\mathrm{mg} \cdot \mathrm{kg}^{-1}\right)$. The absorbencies (of the wells) were determined photometrically at $450 \mathrm{~nm}$ (MRX II. Dynex Technologies. Chantilly. Virginia, USA). DON contents were evaluated by analysis of variance (ANOVA) in SPSS 22.0 (SPSS Inc. Chicago. IL, USA) with a statistical significance set at 95\% $(\mathrm{P}<0.05)$ and $99 \%(\mathrm{P}<0.01)$.

\section{Results}

The analysis of variance (ANOVA) was used to determine DON content in Avena spp. grains from three inoculum methods (Table 1). This analysis revealed significant effects of (1) Avena spp. in each inoculum method used; (2) Year in spray and spray + PE bag/ 
Table 1. ANOVA for deoxynivalenol content in Avena spp. grains after application of three inoculation methods

\begin{tabular}{|c|c|c|c|c|c|}
\hline $\begin{array}{c}\text { Inoculation } \\
\text { method }\end{array}$ & Source of variation & $\begin{array}{l}\text { Degrees of } \\
\text { freedom }\end{array}$ & $\begin{array}{l}\text { Mean } \\
\text { square }\end{array}$ & F-Value & $\mathrm{p}$-Value \\
\hline \multirow[t]{8}{*}{ Spray } & Fusarium spp. & 1 & 0.033 & 0.236 & 0.63 \\
\hline & Year & 1 & 4.590 & 32.48 & 0.00 \\
\hline & Avena & 8 & 1.694 & 11.99 & 0.00 \\
\hline & Fusarium spp. $\times$ year & 1 & 0.000 & 0.00 & 0.95 \\
\hline & Fusarium spp. $\times$ Avena spp. & 8 & 0.340 & 2.40 & 0.17 \\
\hline & Year $\times$ Avena & 8 & 0.799 & 5.65 & 0.00 \\
\hline & Fusarium spp. $\times$ year $\times$ Avena & 8 & 0.233 & 1.65 & 0.11 \\
\hline & residual & 224 & 0.141 & & \\
\hline \multirow{8}{*}{$\begin{array}{l}\text { Spray } \\
+ \text { PE bag } / 24 \mathrm{hrs}\end{array}$} & Fusarium spp. & 1 & 16.715 & 4.767 & 0.03 \\
\hline & Year & 1 & 16.836 & 4.802 & 0.03 \\
\hline & Avena & 8 & 139.944 & 39.916 & 0.00 \\
\hline & Fusarium spp. $\times$ year & 1 & 1.360 & 0.388 & 0.53 \\
\hline & Fusarium spp. $\times$ Avena & 8 & 8.955 & 2.554 & 0.01 \\
\hline & Year $\times$ Avena & 8 & 5.490 & 1.566 & 0.14 \\
\hline & Fusarium spp. $\times$ year $\times$ Avena & 8 & 4.845 & 1.382 & 0.20 \\
\hline & residual & 144 & 3.506 & & \\
\hline \multirow{4}{*}{$\begin{array}{l}\text { Spray } \\
+ \text { PE bag/48 hrs }\end{array}$} & Fusarium spp. & 1 & 1176.552 & 72.712 & 0.00 \\
\hline & Avena & 1 & 237.596 & 14.684 & 0.00 \\
\hline & Fusarium spp. $\times$ Avena & 8 & 87.432 & 5.403 & 0.00 \\
\hline & residual & 60 & 16.181 & & \\
\hline
\end{tabular}

$24 \mathrm{hrs}$ methods applied in field trials during the seasons in 2014 and 2015; (3) Fusarium spp. in spray + PE bag/24 hrs and spray + PE bag/48 hrs methods. Only two-way interactions showed strong influence of a year (Year $\times$ Avena spp.) by spray method and Fusarium spp. (Fusarium spp. $\times$ Avena spp.) by spray + PE bag/24 hrs and spray + PE bag/ $48 \mathrm{hrs}$ methods. Other interactions were not statistically significant (Table 1).

The results presented in Table 2 show that Avena spp. grains from infected panicles by the spray method had the lowest average of DON content. The average contamination of grains from panicles infected by spray + PE bag/24 hrs was 4.04 times higher than by spray and 3.44 times lower than by spray + PE bag/48 hrs methods. The impact of these methods on the accumulation of DON in grains was the most evident in A. ludoviciana. The average accumulation of DON in the grains from genotypes infected by spray $+\mathrm{PE}$ bag/24 hrs method was 2.76 times higher than by spray method and moreover, up to 12.57 times higher than by spray $+\mathrm{PE}$ bag/48 hrs. That resulted to rank this genotype infected by spray $+\mathrm{PE}$ bag/24 hrs method into susceptible one. The statistically significant differ- 
Table 2. Deoxynivalenol content $\left(\mathrm{mg} \cdot \mathrm{kg}^{-1}\right)$ in Avena spp. grains after artificial infection with Fusarium spp. by inoculation methods

\begin{tabular}{|c|c|c|c|c|}
\hline \multirow{2}{*}{ Avena spp. } & \multicolumn{3}{|c|}{ Inoculation method } & \multirow{2}{*}{ Mean } \\
\hline & spray & spray + PE bag $/ 24 \mathrm{~h}$ & spray + PE bag $/ 48$ h & \\
\hline A. abyssinica & $0.28^{\mathrm{a}}$ & $1.36^{\mathrm{ab}}$ & $3.95^{\mathrm{ab}}$ & $1.44^{\mathrm{ab}}$ \\
\hline A. byzantina & $0.27^{\mathrm{a}}$ & $0.75^{\mathrm{a}}$ & $1.74^{\mathrm{a}}$ & $0.76^{\mathrm{a}}$ \\
\hline A. canariensis & $1.24^{\mathrm{c}}$ & $11.21^{\mathrm{d}}$ & $18.61^{\mathrm{e}}$ & $8.76^{\mathrm{e}}$ \\
\hline A. fatua & $0.48^{\mathrm{ab}}$ & $4.81^{\mathrm{c}}$ & $9.60^{\mathrm{bc}}$ & $4.04^{\mathrm{d}}$ \\
\hline A. ludoviciana & $0.50^{\mathrm{ab}}$ & $1.38^{\mathrm{ab}}$ & $17.35^{\mathrm{de}}$ & $4.22^{\mathrm{d}}$ \\
\hline A. nuda & $0.64^{\mathrm{ab}}$ & $1.49^{\mathrm{ab}}$ & $7.76^{\mathrm{abc}}$ & $1.95^{\mathrm{ab}}$ \\
\hline A. sativa & $0.84^{\mathrm{bc}}$ & $2.71^{\mathrm{abc}}$ & $11.66^{\mathrm{cd}}$ & $2.49^{b c}$ \\
\hline A. sterilis & $0.31^{\mathrm{a}}$ & $0.60^{\mathrm{a}}$ & $2.09^{\mathrm{a}}$ & $0.78^{a}$ \\
\hline A. strigosa & $0.48^{\mathrm{ab}}$ & $3.12^{\mathrm{bc}}$ & $11.30^{\mathrm{cd}}$ & $3.69^{\mathrm{bc}}$ \\
\hline Mean & 0.68 & 2.75 & 9.46 & 2.72 \\
\hline
\end{tabular}

Means followed by the same small letters within columns are not significantly different $(\mathrm{p}<0.05)$.

ences in DON accumulation were found between Avena spp. after using these inoculum methods, but the lowest differences between Avena spp. were found after inoculation of panicles by spray method. The most contaminated grains were found from $A$. canariensis after application of all methods (average DON min. $1.24 \mathrm{mg} \cdot \mathrm{kg}^{-1}$ and max. 18.61 $\mathrm{mg} \cdot \mathrm{kg}^{-1}$ ) and the grains with lowest contamination were obtained from A. byzantina and A. sterilis (average DON min. $0.27 \mathrm{mg} \cdot \mathrm{kg}^{-1}$, max. $2.09 \mathrm{mg} \cdot \mathrm{kg}^{-1}$ ).

The results presented in Table 3 show that the average accumulation of DON in Avena spp. after FC infection was the lowest after using the spray method in 2015. The low accumulation of DON from the test set was found in A. sterilis and A. byzantina in all tests. Similarly, the low accumulation of DON was also found in A. ludoviciana and A. abyssinica but only in the case of the spray method. In method spray + PE bag/24 hrs the average DON content in grains from $A$. abyssinica was 2.75 times and A. ludoviciana 2.39 times higher than from $A$. sterilis, which accumulated the smallest amount of DON. In A. ludoviciana the highest accumulation of this toxin from the test set inoculated by spray + PE bag/48 hrs method was detected. The results presented in Table 3 show that the average accumulation of DON in Avena spp. after infection with FG was lower during 2015 in comparison to 2014. After the application of spray $+\mathrm{PE} \mathrm{bag} / 24 \mathrm{hrs}$ and spray $+\mathrm{PE}$ bag/48 hrs method, low DON content was found in grains from A. byzantina and A. sterilis. The highest average DON content was found in A. canariensis grains after the application of each method used in this work. The total average accumulation of DON in Avena spp. after infection with FC isolates was 1.77 times higher than FG (Table 2). The contamination of grains after FC infection was very similar to FG infection by spray and spray $+\mathrm{PE} \mathrm{bag} / 24 \mathrm{hrs}$ methods. However, DON accumulation after infection FC was 2.72 times higher than after FG infection by spray + PE bag/48 hrs. 


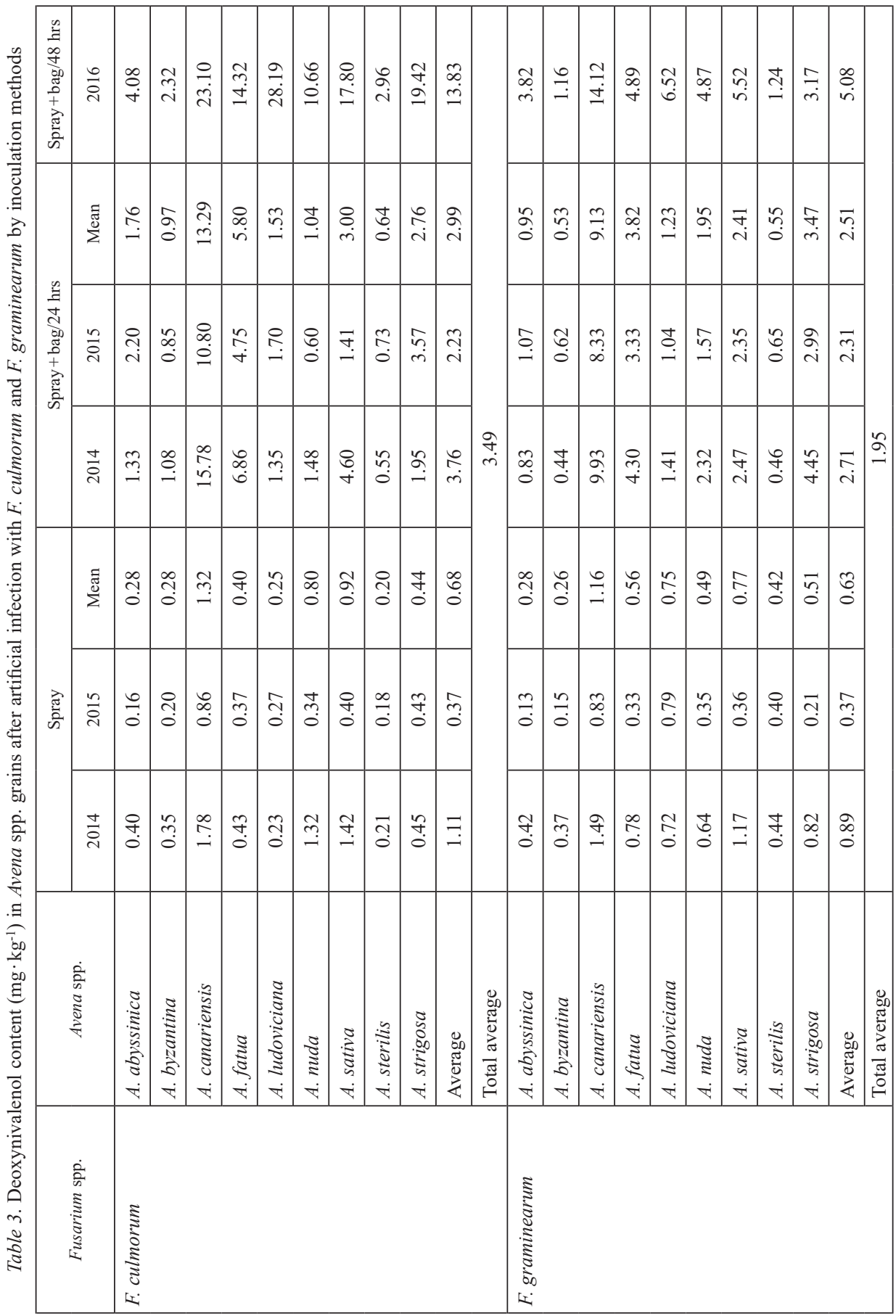




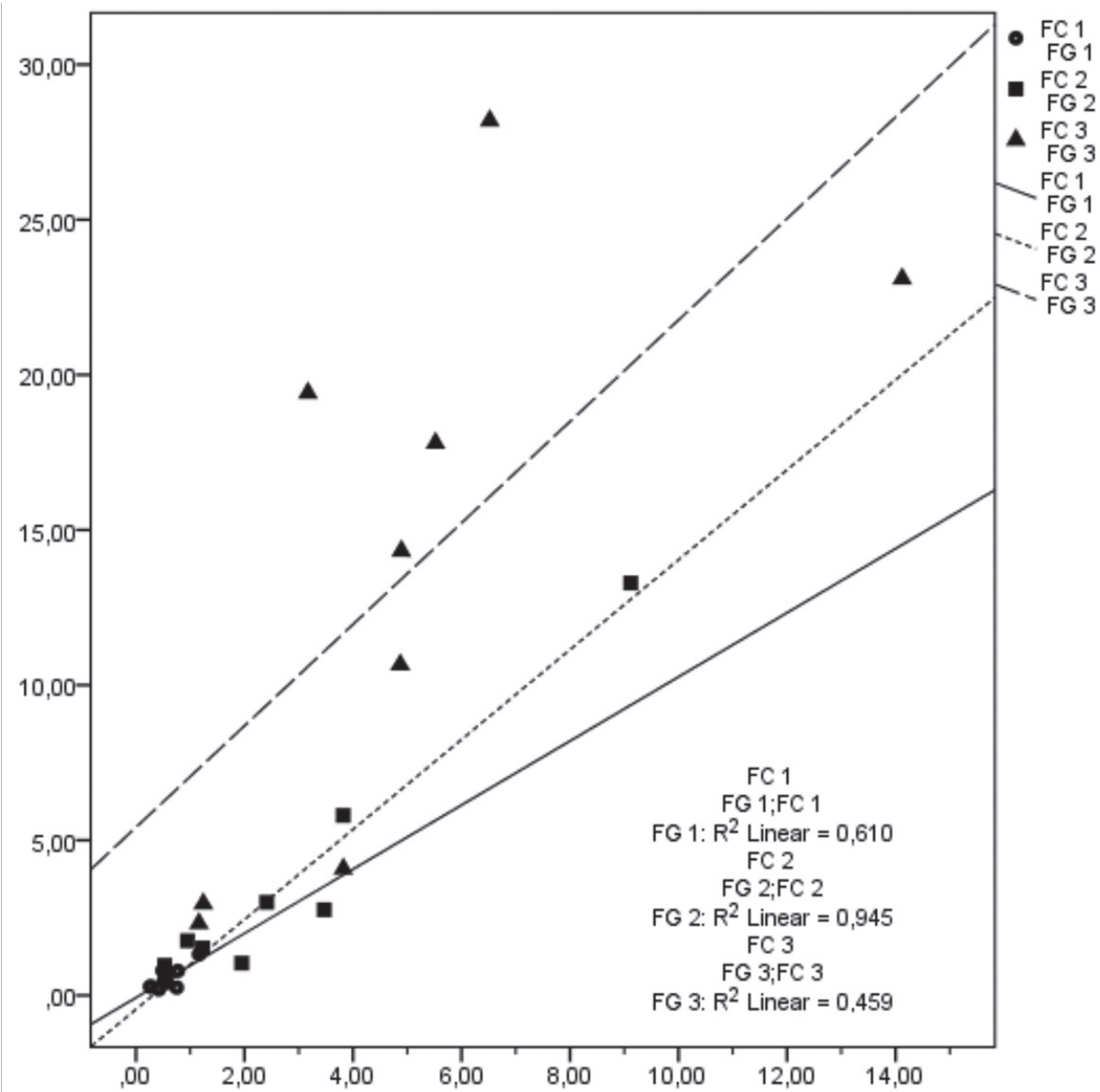

Figure 1. The correlations between deoxynivalenol content after Fusarium culmorum (FC) and F. graminearum (FG) inoculations across inoculation methods (FC1 and FG1 = spray; FC2 and FG2 = spray+ PE bag/24 hrs; FC3 and FG3 $=$ spray + PE bag/48 hrs) by Pearson

The positive correlations between averages of DON content produced by FC and FG in Avena spp. across methods are shown in Fig. 1 (spray $\mathrm{r}=0.678, \mathrm{p}=0.05$; spray $+\mathrm{PE}$ bag/24 hrs $r=0.972, p=0.01$; and spray + PE bag/48 hrs $r=0.781, p=0.05$ ). We found positive correlations between averages of DON content produced by FC and FG across years $(2014 / \mathrm{r}=0.941, \mathrm{p}=0.00 ; 2015 / \mathrm{r}=0.974, \mathrm{p}=0.00 ; 2016 / \mathrm{r}=0.678, \mathrm{p}=0.04)$ and between averages of DON content by FC and FG general $(r=0.824, p=0.00)$.

Total average accumulation of DON in Avena spp. after infection with FC and FG differ only in the case of A. ludoviciana (Fig. 2). The results presented in Fig. 2 show that A. canariensis is most susceptible, and A. byzantina and A. sterilis are resistant to DON accumulation in grains. 


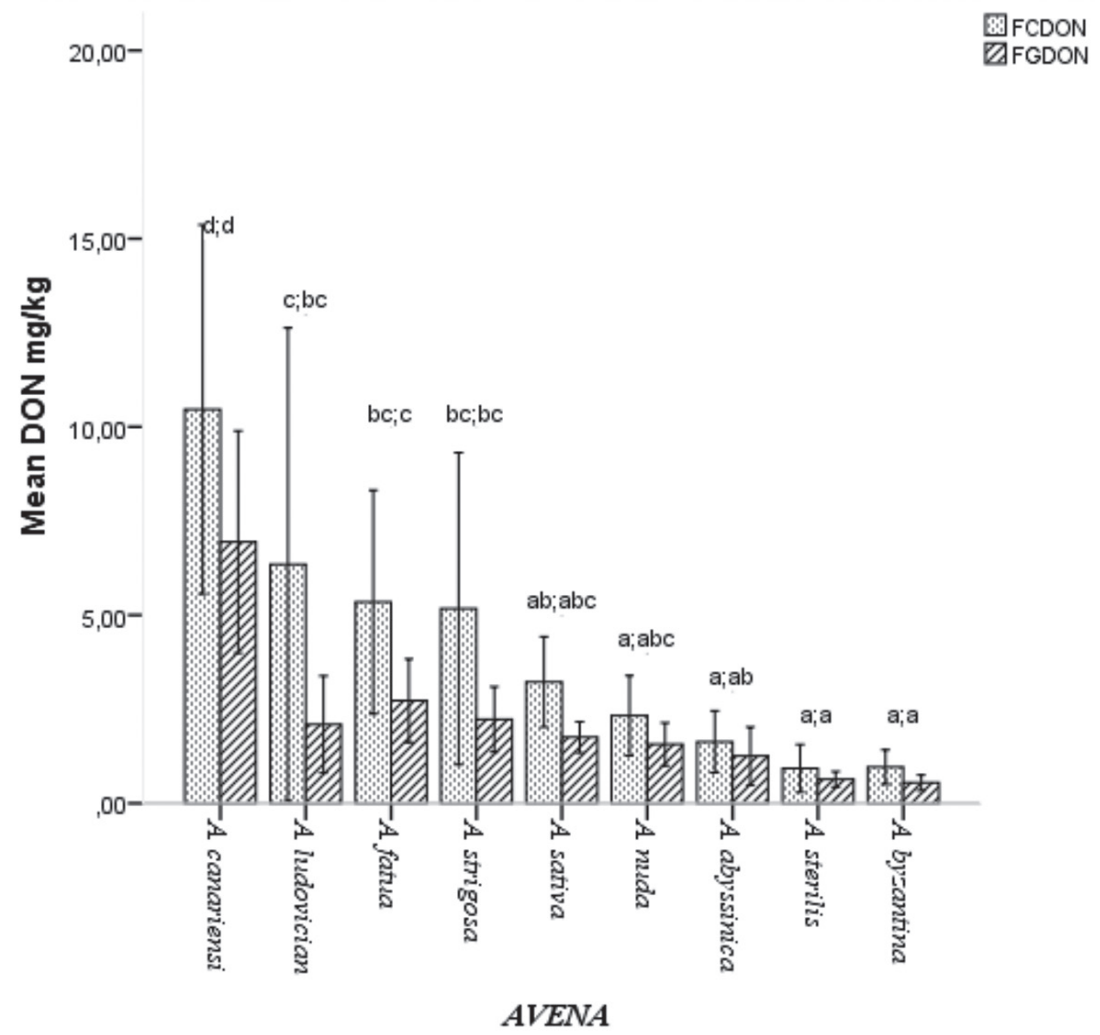

Figure 2. Deoxynivalenol content $\left(\mathrm{mg} \cdot \mathrm{kg}^{-1}\right)$ in nine Avena spp. after artificial inoculation with Fusarium culmorum (FC) and F. graminearum (FG). Error bars represent confidence intervals [level (\%): 95.0] and the same small letters indicate no significant difference $(\mathrm{p}>0.05)$

\section{Discussion}

In our tests we used three variants of spray method, which allowed to create different conditions during initiation of the infective process by the fungi FC and FG. Avena spp. were infected with fungi around anthesis. In this period, oats are most susceptible to Fusarium infection, the fungus enters the floret cavity through the floret apex, this susceptibility decreases as plants develop and mature (Tekle et al. 2012). Xue et al. (2015) found out that oat infected at $50 \%$ anthesis stage was most susceptible to attack, which also manifested itself in the accumulation of DON in grains, while the susceptibility is decreasing at later phases of growth. Subsequent to the infection of plants with FG and FC, DON production is induced (Boenisch and Schäfer 2011). The authors reported that DON biosynthesis is specifically induced in infectious structures that create a fungus in a host plant. Through combination of bioimaging and electron microscopy, infective structures were identified and characterized on wheat. It appears that DON production is 
strongly induced, most likely by the host, at this point of infection (Ilgen et al. 2009). Furthermore, DON has been shown to be essential for the spread of FG from floret to rachis in wheat by preventing host cell wall reinforcement (Jansen et al. 2005).

In our experiments following the application of the spray method, it was shown that the amount of DON was most affected by the year, and then by Avena spp. Strong influence of the year also manifested itself in the interaction of Year $\times$ Avena spp. According to Schmidt-Heydt et al. (2011) the induction of DON production in FC and FG treated samples is significantly affected by abiotic factors such as temperature and water activity. The higher DON content in grains in 2014 compared to 2015 is most probably related to the precipitation, which was higher in May and June (rainfall $=116.2 \mathrm{~mm}$ ) in 2014 than in the very dry year $2015(80.50 \mathrm{~mm})$. Furthermore, the average temperature was higher in May 2014 (temperature $=15.03{ }^{\circ} \mathrm{C}$ ) than in $2015\left(14.80{ }^{\circ} \mathrm{C}\right)$ during the heading/flowering of Avena spp. This corresponds with the study of DON content in oat grains related to weather (Hjelkrem et al. 2017). The continuity was found between the high incidence of DON in oats and warm and humid weather with rainfall whereas low risk of DON occurrence was associated with cold and dry weather, especially at the time of heading/ flowering to harvest (Hjelkrem et al. 2017). In the spray method, the differences between FC and FG treated samples were not detected according to the DON content accumulated in grains of Avena spp.

Methods with PE bag (spray + PE bag/24 hrs and spray + PE bag/48 hrs) ensured high humidity during initiation of infection for $24 \mathrm{hrs}$ and $48 \mathrm{hrs}$. It has been showed that the length of high humidity during initiation of infection has had a significant effect on the amount of DON in the grains and has affected the production potential of the isolates used. According to Schmidt-Heydt (2011) DON production by FC and FG was optimal at 20-25 ${ }^{\circ} \mathrm{C}$ over the 9-day experimental period and at humidity in the high wetness regime over $98 \%$ water activity and during the experiment FC produced more DON than FG. The results from our experiments, where the average DON content in Avena spp. after FC infection was higher than FG clearly demonstrate that FC isolate is more aggressive than FG isolate, as mycotoxin acts as a virulence factor during the propagation of the fungus in the host plant (Proctor et al. 1995; Jansen et al. 2005). Mesterházy (2002) reported that the ability of Fusarium isolates to produce toxins is closely related to the level of their aggression where sometimes an FG, sometimes an FC isolate was stronger, but genotype resistance significantly affects the production of DON. In the most resistant genotypes of wheat, toxin contamination remained low, while the same isolates produced very high levels of toxin in susceptible wheat cultivars.

The significant effect of Avena spp. was showed after FC infection as well as after infection with $\mathrm{FG}$, where grains of $A$. canariensis accumulated the highest level of DON from all tested genotypes and low levels of DON were found in the grains of A. byzantina and A. sterilis. A similar trend of DON accumulation in the grains of each Avena spp. after infection with FC and FG may suggest that the resistance is common for both species, and as well as in wheat, the resistance may be race-non-specific (Mesterházy 2005). Our results correspond with the results published by Gagkaeva (2017) from an experiment in which sixty-six accessions belonging to Avena spp. were infected by isolates of FC. From 
tested genotypes $A$. byzantine and $A$. sterilis, accumulated the smallest amount of DON. In contrast to our findings, they found out resistance to one genotype of $A$. fatua and two genotypes of $A$. sativa. On the other hand, they found out a relatively high susceptibility of $A$. canariensis to the accumulation of DON which corresponds with our results. Three accessions of $A$. fatua and two accessions of $A$. sterilis accumulated high DON content in their experiment. After using spray and spray + PE bag/24 hrs methods from tested genotypes A. ludoviciana showed to be middle resistant against DON accumulation, but after applying the spray + PE bag/48 hrs method it showed to be as a high susceptible genotype. These cases occurred in wheat mainly in genotypes, which at lower infectious pressure proved to be middle resistant genotypes, but at high infectious pressure as a high susceptible. Genes that directly affect DON resistance have not yet been described in Avena spp, but some wheat genes associated with DON resistance and DON response have been discovered (Walter et al. 2008; Hofstad et al. 2016). Testing genotypes against FC and FG showed that within Avena spp. it is possible to find highly efficient sources of resistance against DON accumulation.

The spray methods used in the experiment showed that the length of humidity during the initiation of the infestation process had a significant effect on the different production potential of FC and FG. In the case of very favourable conditions for the development of FHB, breakage of mild resistance can occur and the genotype becomes very sensitive to the accumulation of DON as in the case of $A$. ludoviciana. In our experiments, we have found out that several genotypes of Avena spp. accumulated more DON in the grains after artificial inoculation by FC than FG, especially when using PE bags. A. byzantine and A. sterilis showed good resistance to the accumulation of DON and these can be included in the oat breeding process as a source of resistance to DON-producing Fusarium.

\section{Acknowledgements}

This research was supported by the Slovak Research and Development Agency (project No. APVV-17-0113) and by OP Research and Development (No. ITMS: 26220220194) from European Regional Development Fund.

\section{References}

Bjørnstad, Å., He, X., Tekle, S., Klos, K., Huang, Y.F., Tinker, N.A., Dong, Y., Skinnes, H. 2017. Genetic variation and associations involving Fusarium head blight and deoxynivalenol accumulation in cultivated oat (Avena sativa L.). Plant Breed. 136(5):620-636.

Boenisch, M.J., Schäfer, W. 2011. Fusarium graminearum forms mycotoxin producing infection structures on wheat. BMC Plant Biology 11:110.

Commission Regulation (EC) No 1126/2007 of 28 September 2007 amending Regulation (EC) No 1881/2006 setting maximum levels for certain contaminants in foodstuffs. Off. J. Eur. Union L. 255:14-17.

Edwards, S.G., Imathiu, S.M., Ray, R.V., Back, M., Hare, M.C. 2012. Molecular studies to identify the Fusarium species responsible for HT-2 and T-2 mycotoxins in UK oats. Int. J. Food Microbiol. 156(2):168175.

Edwards, S.G. 2017. Impact of agronomic and climatic factors on the mycotoxin content of harvested oats in the United Kingdom. Food Addit. Contam. A 34(12):2230-2241. 
Fredlund, E., Gidlund, A., Sulyok, M., Börjesson, T., Krska, R., Olsena, M., Lindblad, M. 2013. Deoxynivalenol and other selected Fusarium toxins in Swedish oats - Occurrence and correlation to specific Fusarium species. Int. J. Food Microbiol. 167(2):276-283.

Gagkaeva, T., Gavrilova, O., Orina, A.S., Blinova, E.V., Loskutov, I.G. 2017. Response of wild Avena species to fungal infection of grain. The Crop Journal 5(6):499-508.

Gagkaeva, T., Gavrilova, O., Yli-Mattila, T., Loskutov, I. 2011. Evaluation of oat germplasm for resistance to Fusarium head blight. Plant Breeding Seed Sci. 64:15-22.

Gavrilova, O.P., Orina, A.S., Gagkaeva, T., Loskutov, I.G. 2016. Evaluation of resistance of Avena L. genotypes to fusarium infection and accumulation of mycotoxins. Dostizheniya nauki i tekhniki APK 30(1):25-29.

Hietaniemi, V., Rämö, S., Yli-Mattila, T., Jestoi, M., Peltonen, S., Kartio, M., Sieviläinen, E., Koivisto, T., Parikka, P. 2016. Updated survey of Fusarium species and toxins in Finnish cereal grains. Food Addit. Contam. A 33(5):831-848.

Hjelkrem, A.G.R., Torp, T., Brodal, G., Aamot, H.U., Strand, E., Nordskog, B., Dill-Macky, R., Edwards, S.G., Hofgaard, I.S. 2017. DON content in oat grains in Norway related to weather conditions at different growth stages. Eur. J. Plant Pathol. 148(3):577-594.

Hofgaard, I.S., Aamot, H.U., Torp, T., Jestoi, M., Lattanzio, V.M.T., Klemsdal, S.S., Waalwijk, C., Van der Lee, T., Brodal, G. 2016. Associations between Fusarium species and mycotoxins in oats and spring wheat from farmers' fields in Norway over a six-year period. World Mycotoxin J. 9(3):365-378.

Hofstad, A.N., Nussbaumer, T., Akhunov, E., Shin, S., Kugler, K.G., Kistler, H.C., Mayer, K.F., Muehlbauer, G.J. 2016. Examining the Transcriptional Response in Wheat Fhb1 Near-Isogenic Lines to Fusarium graminearum Infection and Deoxynivalenol Treatment. Plant Genome-US 9(1):1-15.

Ilgen, P., Hadeler, B., Maier, F.J., Schafer, W. 2009. Developing kernel and rachis node induce the trichothecene pathway of Fusarium graminearum during wheat head infection. Mol. Plant Microbe In. 22(8):899-908.

Jansen, C., von Wettstein, D., Schäfer, W., Kogel, K.-H., Felk, A., Maier, F.J. 2005. Infection patterns in barley and wheat spikes inoculated with wild-type and trichodiene synthase gene disrupted Fusarium graminearum. Proc. Natl. Acad. Sci. USA 102(46):16892-16897.

Lásztity, R. 1998. Oat grain - a wonderful reservoir of natural nutrients and biologically active substances. Food Rev. Int. 14(1):99-119.

Mesterházy, Á. 1978. Comparative analysis of artificial inoculation methods with Fusarium spp. on winter wheat varieties. Phytopath. Z. 93(1):12-25.

Mesterházy, Á. 2002. Role of deoxynivalenol in aggressiveness of Fusarium graminearum and F. culmorum and in resistance to Fusarium head blight. Eur. J. Plant Pathol. 108(7):675-684.

Mesterházy, Á., Bartók, T., Kászonyi, G., Varga, M., Tóth, B., Varga, J. 2005. Common Resistance to Different Fusarium spp. Causing Fusarium Head Blight in Wheat. Eur. J. Plant Pathol. 112(3):267-281.

Meydani, M. 2009. Potential health benefits of avenanthramides of oats. Nutr Rev. 67(12):731-735.

Nathanail, A.V., Syvähuoko, J., Malachová, A., Jestoi, M., Varga, E., Michlmayr, H., Adam, G., Sieviläinen, E., Berthiller, F., Peltonen, K. 2015. Simultaneous determination of major type A and B trichothecenes, zearalenone and certain modified metabolites in Finnish cereal grains with a novel liquid chromatographytandem mass spectrometric method. Anal. Bioanal. Chem. 407(16):4745-4755.

Nirenberg, H. 1976. Untersuchungen über die morphologische und biologische Differenzierung in der Fusarium Sektion Liseola. Mitt. Biol. Bundesanst. Land-Forstwirtsch. Berlin-Dahlem 169:1-117.

Othman, R.A., Moghadasian, M.H., Jones, P.J. 2011. Cholesterol-lowering effects of oat $\beta$-glucan, Nutr. Rev. 69(6):299-309.

Proctor, R.H., Hohn, T.M., McCormick, S.P. 1995. Reduced virulence of Gibberella-zeae caused by disruption of a trichothecene toxin biosynthetic gene. Mol. Plant Microbe In. 8(4):593-601.

Schmidt-Heydt, M., Parra, R., Geisen, R., Magan, N. 2011. Modelling the relationship between environmental factors, transcriptional genes and deoxynivalenol mycotoxin production by strains of two Fusarium species. J. R. Soc. Interface 8(54):117-126.

Schöneberg, T., Jenny E., Wettstein, F.E., Bucheli, T.D., Mascher, F., Bertossa, M., Musa, T., Seifert, K., Gräfenhan, T., Keller, B., Vogelgsang, S. 2018. Occurrence of Fusarium species and mycotoxins in Swiss oats - Impact of cropping factors. Eur. J. Agron. 92:123-132. 
Tekle, S., Dill-Macky, R., Skinnes, H., Tronsmo, A.M., Bjørnstadet, Å. 2012. Infection process of Fusarium graminearum in oats (Avena sativa L.). Eur. J. Plant Pathol. 132(3):431-442.

Tekle, S., Lillemo, M., Skinnes, H., Reitan, L., Buraas, T., Bjørnstadet, Å. 2018. Screening of oat accessions for fusarium head blight resistance using spawn-inoculated field experiments. Crop Sci. 58(1):143-151.

Walter, S., Brennan. J., Arunachalam, C., Ansari, K.I., Hu, X., Khan, M.R., Trognitz, F., Trognitz, B., Leonard, G., Egan, D., Doohan, F.M. 2008. Components of the gene network associated with genotype-dependent response of wheat to the Fusarium mycotoxin deoxynivalenol. Funct. Integr. Genomic. 8(4):421-427.

Welch, R.W. 1995. Oats in human nutrition and health. In: The oat crop - Production and utilization. Ed.: Welch, R.W., Chapman \& Hall, London. pp. 433-479.

Xu, X., Madden, L.V., Edwards, S.G. 2014. Modeling the effects of environmental conditions on HT2 and T2 toxin accumulation in field oat grains. Phytopathol. 104(1):57-66.

Xue, A.G., Chen, Y., Marchand, G., Guo, W., Ren, Ch., Savard, M., McElroy, A.R.B. 2015. Timing of inoculation and Fusarium species affect the severity of Fusarium head blight on oat. Can. J. Plant Sci. 95(3):517524 . 